\title{
Probing for Informal Work Activity
}

\author{
Katharine G. Abraham ${ }^{1}$ and Ashley Amaya ${ }^{2}$
}

\begin{abstract}
The Current Population Survey (CPS) is the source of official US labor force statistics. The wording of the CPS employment questions may not always cue respondents to include informal work in their responses, especially when providing proxy reports about other household members. In a survey experiment conducted using a sample of Amazon Mechanical Turk respondents, additional probing identified a substantial amount of informal work activity not captured by the CPS employment questions, both among those with no employment and among those categorized as employed based on answers to the CPS questions. Among respondents providing a proxy report for another household member, the share identifying additional work was systematically greater among those receiving a detailed probe that offered examples of types of informal work than among those receiving a simpler global probe. Similar differences between the effects of the detailed and the global probe were observed when respondents answered for themselves only among those who had already reported multiple jobs. The findings suggest that additional probing could improve estimates of employment and multiple job holding in the CPS and other household surveys, but that the nature of the probe is likely to be important.
\end{abstract}

\section{Introduction}

Information on employment and hours of work is critical to policy makers and other decision makers for assessing the state of the labor market and the economy more broadly. In the United States, much of this information comes from the Current Population Survey (CPS), a monthly survey of approximately 60,000 households carried out by the U.S. Census Bureau on behalf of the Bureau of Labor Statistics (BLS). In the CPS, an individual is considered to be employed if he or she "did any work at all for pay or profit during the survey reference week. This includes all part-time and temporary work, as well as regular full-time, year-round employment" (Bureau of Labor Statistics, undated).

One potential concern about the CPS data is that the wording of the survey's employment questions may not adequately cue respondents to report work activity outside of a conventional job or business. The CPS employment questions are asked for each household member age 16 and older. The initial employment question asks whether the household member did any work during the survey reference week for 'pay' (or, if

1 University of Maryland, Joint Program in Survey Methodology and Department of Economics, College Park, Maryland, 20742, U.S.A. Email: kabraham@umd.edu.

${ }^{2}$ RTI International, Survey Research Division, 70113 St NW, \#750, Washington D.C., U.S.A. Email: aamaya@rti.org.

Acknowledgments: The authors are grateful to Frederick G. Conrad, Monica Dashen, Susan N. Houseman, Frauke Kreuter, and James R. Spletzer for helpful comments and suggestions on an earlier draft of the paper. Support for collection of the data analyzed in the paper was provided by the U.S. Census Bureau under Contract YA132312CN0037 with the University of Maryland, which provided support for the Joint Program in Survey Methodology (JPSM) generally and the 2016 JPSM Survey Practicum specifically. 
applicable, for 'pay or profit'). Later questions in the sequence ask about having more than one 'job' (or, if applicable, more than one 'job or business'). The "pay or profit" and "job or business" formulations are used in cases in which the CPS respondent has indicated that someone in the household has a business. It is not clear, however, that respondents necessarily will think of money earned through informal work activity as either 'pay' or 'profit' or consider such activity to be a 'job' or 'business.' The consequence may be that the reporting of informal work activity is incomplete.

The use of proxy respondents is a second potential challenge to accurate reporting. Although CPS interviewers attempt to collect employment information from each household member age 16 years or older, time and availability constraints often lead to the use of a proxy reporter, a household member who answers the survey questions on behalf of other household members. Responses for roughly half of CPS sample persons are collected from proxy reporters (U.S. Census Bureau 2006). Even if the respondent understands that all work to earn money should be reported, irregular or casual work performed by other household members may be less salient to the proxy respondent than similar work performed by the respondent herself and thus less likely to be reported. In some cases, the respondent simply may not know about informal work performed during the survey reference period by other household members.

This article seeks to understand the nature of potential biases in the reporting of work activity in the CPS and similar surveys. Our first research question can be stated:

1) Is there informal work for pay or profit done during the survey reference week that is not captured by the standard Current Population Survey (CPS) employment questions?

To answer this research question, we examine whether asking questions focused specifically on informal work as a follow-up to the standard CPS employment questions identifies additional work activity. We also are interested in whether different ways of asking such added questions are more or less effective and in whether this varies according to whether a respondent is reporting for themselves versus another household member or, in the latter case, according to the relationship of the respondent to the other household member:

2) Does the way in which questions that probe for informal work are asked affect the number of additional jobs identified?

3) Does the relative effectiveness of different ways of probing for informal work vary by whether the survey respondent is answering for herself (self-report) or for another household member (proxy report)? If answering for another household member, does the relative effectiveness of different ways of probing vary by the closeness of the survey respondent to the other household member?

Finally, we are interested in the potential effects of under-reporting of informal work during the survey reference week on key labor force measures:

4) How does any under-reporting of informal work in answering the standard CPS questions affect estimates of the employment rate (the share of the sample that is categorized as employed) and the multiple job holding rate (the share of employed persons in the sample who hold more than one job)? 


\section{Background}

To understand how question wording might affect reports of work activity, we must first identify how respondents formulate responses. The most common model of the response process suggests four steps: (1) understanding the question, (2) recall, (3) inference and estimation, and (4) mapping the answer onto the response format and editing the response (Sudman et al. 1996; Tourangeau et al. 2000). We limit our discussion to the first two of these steps because they are the most relevant to our research questions and experimental conditions.

Before a respondent can provide a response to a survey question, she must first understand what information is being requested. Even questions that appear to be clear can be interpreted in different ways. For example, in one study, respondents were asked: "Have you smoked at least 100 cigarettes in your entire life?" Respondents disagreed on whether to include puffs where they did not inhale, whether to count cigarettes they had only partially smoked, and what constituted a cigarette (Schober et al. 2018). This sort of disconnect is due, in part, to the difference between literal interpretation and pragmatic interpretation. Individuals want to be responsive to what they think the researcher wants to know (pragmatic interpretation), regardless of exactly what was asked (literal interpretation) (Schwarz 1999). A respondent answering the CPS employment questions might decide that informal or irregular work activity that occurred during the survey reference week is not part of what the interviewer is asking about. For example, someone who performed as a magician at weekend children's parties or maintained a blog that generated ad revenue might think of this activity as a 'hobby' and not as 'work', and fail to report it when asked the standard CPS questions. While any misconstruing of a question on the part of a respondent is problematic for achieving accurate estimates, there is no reason to think that the severity of this problem should differ between self and proxy reports. In either case, a probe asking specifically about informal work may change the respondent's understanding of what they should be reporting and thus uncover previously unreported work activity.

In the second step of the response process, the respondent must recall information relevant to formulating a response. They will use cues such as 'work', 'pay or profit', 'job or business,' and the reference week from the question wording and survey context to search their memory. Poor cues will increase the chance of retrieval failure (Tourangeau 2000). Because richer information is stored about the self than about others (Kuiper and Rogers 1979), strong cues may be especially important for proxy reporting. To the extent that individuals store more information about events that involve them directly, even a weak cue may spur retrieval of a given event, whereas stronger cues may be required to activate the retrieval of information about other individuals' activities. In the context of collecting information about informal work activity, we would expect a question that provides specific examples of the types of work that may have been performed (e.g., doing yard work or driving for a ridesharing service) to activate a respondent's memory more successfully than a question that asks in more general terms about informal work activity. We would expect this to be more the case for proxy reports than for self-reports and, among proxy reports, perhaps more so for individuals with whom the respondent has weaker ties (e.g., a roommate or other unrelated household member) as opposed to those with whom the respondent has stronger ties (e.g., a spouse). 
The use of dispositional knowledge also may lead to failure in the recall process. Individuals may have two distinct types of knowledge about others: situational and dispositional (Schwarz and Wellens 1997). Situational knowledge includes details about specific events whereas dispositional knowledge is information that can be inferred about an individual based on her typical behavior. In a study of consumer expenditures, for example, respondents used a combination of situational and dispositional knowledge to report their own spending behavior but relied primarily on dispositional knowledge when reporting on behalf of their spouse (Dashen 2000). When individuals use dispositional knowledge to answer questions about employment, they may be less likely to report sporadic or casual work activity because it is not a 'usual' behavior (Sudman et al. 1996; Schwarz and Wellens 1997). This reasoning suggests that, to the extent that probing encourages the respondent to tap into situational knowledge, it may be differentially effective for uncovering added informal work among proxy reports compared to self-reports.

Individuals also may fail to retrieve the necessary information if it was not encoded in the first place. While this should be relatively rare for self-reports of employment, it could be more of an issue for proxy reporting. If another household member did work during the reference week but did not tell the respondent, the respondent would not know to report it. More generally, it may be difficult for a proxy respondent to estimate the extent of another household member's participation in an irregular behavior over a particular interval of time (Phillips et al. 2006). The closeness of proxy reporters to the subject of their reporting has been found to be correlated with the accuracy of the proxy report, perhaps because individuals who are closer to one another are more likely to share information about their activities (Bower and Gilligan 1979; Phillips et al. 2006). As an example, Kojetin and Miller (1993) found stronger agreement between spouses' reports about their partners' spending and the partners' own reports than between parents' reports about their children's spending and the children's own reports. In general, making spending decisions jointly with another household member, discussing spending with the other household member, or observing items that the other household member may have purchased all contributed to stronger agreement between reports made by the proxy respondent and those made by the person doing the spending. If lack of encoding is problematic in the context of reporting about work activity, we might expect the effects of probing to differ depending on the relationship between the respondent and the person about whom she is reporting. In this case, probing could be more effective when used to elicit information about individuals, such as a spouse who are closer to the respondent, since the information is more likely to have been encoded in the first place, and less effective when used to elicit information about other household members.

Three primary methods have been tested to improve accuracy of reports about behavior. First, definitions have been used to clarify questions, thus improving comprehension. In an experiment described by Fowler (1992), definitions intended to ensure that respondents' interpretations of a set of questions related to health behaviors were consistent with the researcher's intent were provided to half of the participants but not to the others. While no information was collected on respondent interpretation, the distribution of responses differed significantly between the two conditions. Inclusion of definitions or instructions can be more important in complex situations. For example, in one experiment, subjects asked a series of questions about employment status, housing, and household purchases 
based on complex fictional scenarios answered accurately about $87 \%$ of the time when interviewers had the flexibility to clarify definitions, but just $28 \%$ of the time when no definitions were provided. Answers to the same questions based on simpler scenarios were accurate $97 \%$ or more of the time regardless of whether the interviewer had the opportunity to provide clarification (Schober and Conrad 1997).

Second, adding examples to questions offers additional cues that the respondent may be able to use to recall more complete information. The choice of examples provided may affect the responses that are given. In a study of food consumption, Tourangeau et al. (2014) varied the examples for different food categories by the frequency of consumption (e.g., bread versus barley for grains) and by whether the item would be considered a typical example (e.g., milk versus sour cream for dairy). Overall, individuals reported more consumption when any examples were provided. Further, when asked to list what they ate, they were more likely to mention consumption of the example items. This suggests that individuals retrieve enough information to make a judgement but do not try to recall everything.

Finally, and perhaps most relevant for this study, researchers have tested the use of decomposed questions to offer additional cues and enhance recall. Menon (1997) conducted a diary experiment in which individuals were asked either open-ended questions about the number of times they had done each of six behaviors or a set of questions that explicitly cued the respondent to think about the different circumstances under which each of the same things might have been done. The second, decomposed condition improved the accuracy of recall for the three irregular behaviors studied (making unplanned stops to talk to friends, snacking, and drinking from a water fountain), but not for the regular behaviors (washing hair, having dinner, and attending class).

Other research has identified circumstances under which decomposed questions may perform less well. In a survey experiment reported by Belli et al. (2000), respondents either were asked a simple question about the total number of local or long-distance phone calls they had made during a specified period or were asked decomposed questions about the same behavior that cued the respondent to think separately about calls at different times or to different destinations. Subjects who received the decomposed question had a greater tendency to over-report the number of phone calls they had made than subjects who received the simple question. Members of the study population in the Belli et al. (2000) study made a sufficiently large number of phone calls that they most likely used an estimation strategy to formulate their answers rather than enumerating each call individually (Blair and Burton 1987). We would expect respondents reporting on informal work activities during the prior week to enumerate rather than estimate, meaning that the findings reported by Menon (1997) are likely to be more applicable to our context than the findings reported by Belli et al. (2000).

Additional research has suggested that probing or decomposed questions also may result in overreporting due to forward telescoping, that is, the inclusion of activities that in fact had occurred prior to the specified reference period (Sudman and Bradburn 1973). Forward telescoping is more likely to occur when events are highly salient. Events that are less salient are more likely to suffer from backward telescoping, that is, the exclusion of events that occurred within the reference period because individuals think they occurred longer ago. To the extent that work identified through the additional questions is work that is less salient, the results will be more likely to suffer from backward than forward 
telescoping, trending the additional work identified toward zero (Brown et al. 1985). Moreover, telescoping (of any kind) is more likely to occur the further back the period for which the respondent is asked to recall (Martin 2006). Given that our survey asks about events that occurred over the most recent calendar week, we would not expect telescoping to be a large problem in our context. On balance, the existing literature leads us to expect that adding questions to the CPS questionnaire to identify previously unreported work should improve the accuracy of the information collected.

The material importance of any potential underreporting of informal work activity for our understanding of the labor market will depend in part on the prevalence of such activity in the CPS target population. This is something that several recent surveys have attempted to measure. Robles and McGee (2016) analyzed data from the Enterprising and Informal Work Activities (EIWA) survey fielded by the Federal Reserve Board in October and November of 2015. In their sample, during the six months prior to the survey, $36 \%$ of the adult population participated in informal work that involved either selling or renting property or providing services. The estimate from the 2016 Survey of Household Economics and Decision making (SHED), which included similar questions, is that $28 \%$ of adults earned money from informal work outside of a main job during the month prior to the survey (Board of Governors of the Federal Reserve System 2017). The two waves of the Survey of Informal Work Participation (SIWP) carried out during 2015 asked whether respondents were "currently engaged" in informal paid activity or side jobs, exclusive of selling property, renting property or responding to surveys (Bracha and Burke 2019). This was the case for $21 \%$ of adults age 21 and older categorized as employed, $25 \%$ of those categorized as unemployed, and $12 \%$ of those categorized as out of the labor force based on the CPS employment questions. An important caveat is that all three of these estimates are based on online panel surveys. One might be concerned that engagement in other sorts of informal work is higher among those willing to participate in an online panel than among the general population. While perhaps the case, at least in the SHED, even after excluding all informal work done by anyone who reported any online work, the estimated prevalence of informal work activity remained substantial (Abraham and Houseman 2018).

Existing research provides some insights regarding the set of questions about the measurement of informal work that motivate our research. In a study based on data collected during the early 1990s, Martin and Polivka (1995) explored the effect of probing for informal work activity on measured employment rates. In one portion of their study, household survey respondents were asked questions very similar to the current CPS employment sequence. Then, in cases in which there was at least one adult member of the respondent's household with no reported employment, a question about informal work activity was asked regarding the first such person listed on the household roster. Additional work activity identified through this probing raised the estimated employment rate by 2.3 percentage points, with proportionally larger effects for household members under age 20 and age 65 and older. Martin and Polivka did not attempt to learn about underreporting of informal work as a secondary work activity (i.e., about multiple job holding) or about differences in the effects of probing for self versus proxy reporters, nor did they experiment with alternative wordings for their probe.

More recently, analyzing data from the two waves of the SIWP fielded in 2015, Bracha and Burke (2019) estimated that accounting for informal work activity identified through 
probing would raise the overall employment rate by 4.5 percentage points above that estimated based on responses to the CPS employment questions and raise the multiple job holding rate by more than 11 percentage points. In contrast to Martin and Polivka (1995), Bracha and Burke asked first about informal work and then administered the CPS employment questions. This question ordering could have affected the responses to the CPS questions and thus their conclusions. The wording of their question about informal work - which asks whether a respondent is "currently engaged" in such work rather than about whether the respondent did any such work during the survey reference period - is also potentially problematic. Bracha and Burke (2019) do not provide evidence on possible differences in the reporting behavior of self-reporters versus proxy reporters, nor was their study designed to learn about the effectiveness of different ways of asking about respondents' participation in informal work.

Another relevant study is Katz and Krueger (2019a), which reported on a 2015 survey of respondents recruited via the Mechanical Turk website, Amazon's crowdsourcing platform, that was designed primarily to learn whether people answering the CPS employment questions under-report multiple job holding. They first asked the CPS employment questions and then asked "Did you work on any gigs, HITS or other small paid jobs last week that you did not include in your answer to the previous question?" Taking the additional small jobs mentioned by respondents into account raised the share of workers in the Katz and Krueger sample who were multiple job holders from $39 \%$ to $77 \%$. Similar to the other studies we have discussed, the Katz and Krueger study was not designed to shed light on possible differences between the reporting behavior of selfreporters versus proxy reporters nor to assess the relative effectiveness of different ways of probing to learn about informal work activity.

Finally, in a novel analysis, Allard and Polivka (2018) used data from the American Time Use Survey (ATUS) to gauge the effects of accounting for informal work on the employment and multiple job holding rates. The ATUS, which uses the CPS as a sampling frame, includes CPS-style questions about individuals' labor force status and also collects information on each respondent's allocation of time during one 24-hour period. Allard and Polivka focused on time devoted to labor-intensive income-generating activities such as hobbies, crafts, food, performances or services that are not part of a job or business. They estimated that, in the ATUS over the 2012-2016 period, accounting for such activities would have raised the employment rate by between $0.4 \%$ and $3.0 \%$ and raised the multiple job-holding rate by between $3.0 \%$ and $20.7 \%$. In both cases, the range reflects uncertainty about the extent to which average daily participation in such activities reflects the same people engaging in the activity on multiple days as opposed to different people engaging in the activity on different days. These estimates suggest that the standard CPS questions miss relatively little informal work activity, but depend both on the definition of incomegenerating activities adopted and, perhaps more importantly, on the ATUS doing a good job of capturing time devoted to those activities.

\section{Methods}

To answer our research questions, we use data from the 2016 Joint Program in Survey Methodology (JPSM) practicum project. For this project, a task visible only to US 
residents was posted to the Mechanical Turk website, asking for individuals to complete a survey about employment referred to in the posting as the Current Employment Survey. Individuals who clicked on the task were told that they would receive USD 2.50 for completion of a survey about the employment status of themselves and other household members. A total of 4,991 people completed the survey on August 16 and 17, 2016, taking an average of 13.55 minutes to answer the questions asked. Given the non-probabilistic nature of the survey, response rates were not calculated. We excluded 52 cases due to item non response, and analysis was conducted on the remaining 4,939 completed interviews.

The first section of the survey collected information on the characteristics of all members of a respondent's household. It included questions concerning age, sex, education, race and ethnicity, marital status and relationship to the household respondent (opposite sex spouse, opposite sex unmarried partner, same-sex spouse, same-sex unmarried partner, child, grandchild, parent, brother/sister, other relative, foster child, housemate/roommate, roomer/boarder or other non-relative). The second section of the survey asked questions to identify each household member's employment status; for those who were employed, whether they held more than one job; and, as applicable, the hours worked on the main and other jobs. With the exception of some experimental questions concerning sexual orientation and gender identity, all of the questions about household members' characteristics and work activity were taken directly from the CPS questionnaire. The use of the CPS employment questions on the JPSM practicum survey means that the responses can be used to construct CPS-like measures of both employment and multiple job holding during the survey reference week ("last week," defined as the most recent completed week beginning on a Sunday and ending on a Saturday).

For the respondent (in single adult households) or for one randomly-selected member of the household (in multiple adult households), the CPS employment questions were followed by additional questions probing for activity to earn money outside of a regular job. This is the sample of people on which the analysis reported here is based. As can be seen in Table 1, the analysis subjects are younger and considerably more educated than the population as a whole.

The specific questions asked about informal work activity were varied experimentally. In one treatment condition, randomly assigned to half the cases, respondents were asked a global yes/no question about whether any such activity had occurred during the survey reference week (the global question). If no work activity had been reported for the subject household member in response to the standard CPS questions, the global question was:

Sometimes people who don't have a job do other things to earn money. Did [you/[NAME]] do other things to earn money last week?

For those with work activity reported in answer to the CPS questions, the global question was:

Sometimes, in addition to working at a job [or business] where there is a definite arrangement for regular work on a continuing basis, people do other things to earn money. Outside of a job [or business], did [you/[NAME]] do other things to earn money last week? 
Table 1. Characteristics of Analysis Sample versus American Community Survey Estimates (Percent Distributions).

\begin{tabular}{|c|c|c|c|}
\hline & Respondent & $\begin{array}{c}\text { Other } \\
\text { household } \\
\text { members }\end{array}$ & $\begin{array}{c}\text { ACS } \\
(2016)^{3}\end{array}$ \\
\hline \multicolumn{4}{|l|}{ Age } \\
\hline $18-24 / 16-24^{1}$ & 11.7 & 18.7 & 12.8 \\
\hline $25-34$ & 45.8 & 31.7 & 17.7 \\
\hline $35-44$ & 23.9 & 17.5 & 16.6 \\
\hline $45-54$ & 11.1 & 14.1 & 17.7 \\
\hline $55-64$ & 5.7 & 11.4 & 16.4 \\
\hline 65 and over & 1.7 & 6.6 & 18.9 \\
\hline Female $^{2}$ & 50.6 & 47.3 & 51.4 \\
\hline \multicolumn{4}{|l|}{ Education } \\
\hline Less than high school & 0.3 & 6.7 & 12.6 \\
\hline High school & 8.7 & 21.3 & 27.7 \\
\hline Some college or associate degree & 36.2 & 33.6 & 31.0 \\
\hline Bachelors degree or higher & 54.7 & 38.3 & 28.7 \\
\hline \multicolumn{4}{|l|}{ Race/ethnicity } \\
\hline Hispanic & 7.3 & 10.7 & 16.0 \\
\hline Non-hispanic white & 73.8 & 70.9 & 65.5 \\
\hline Non-hispanic african american & 7.0 & 6.9 & 12.3 \\
\hline Non-hispanic other race & 8.0 & 8.9 & 4.8 \\
\hline Non-hispanic multiracial & 3.9 & 2.6 & 1.5 \\
\hline Sample size & 2,704 & 2,235 & - \\
\hline
\end{tabular}

${ }^{1}$ All survey respondents were age 18 or older, but respondents were asked to report for other household members age 16 and older. The survey sample includes $N=93$ other household members age 16 or 17 . The ACS numbers show the age distribution of the population age 18 and older.

${ }^{2}$ The survey sample includes $\mathrm{N}=22$ respondents and $\mathrm{N}=19$ other household members reported as transgender or not identifying as either male or female, or for whom no report on gender identity was provided. They are included in the denominator when calculating the percent female in our sample.

${ }^{3}$ All sample distributions are significantly different from the corresponding ACS distributions at $p<0.001$.

In these questions, as applicable, the text filled based on the person selected (e.g., if the respondent is answering about another household member, NAME refers to that person's name) and whether or not the respondent had reported work by the individual in a family business.

In the second treatment condition, survey respondents were asked essentially the same question, but with potential informal work activity decomposed into seven different categories (the detailed question). The seven categories of work activity outside of a regular job that a respondent might report were (1) provided services to other people, (2) provided services to a self-employed individual or business, (3) performed as an actor, musician or entertainer, (4) drove for a ridesharing service, (5) assisted with medical, marketing, or other research, (6) posted videos, blog posts, or other content online, or (7) did other informal work or side job. Examples were provided for all but the 'other' category.

For anyone categorized as CPS employed for whom informal work was reported, the respondent was asked to indicate whether the informal work mentioned in response to additional probing had been included in the CPS job count. Both among those who 
received the global probe and among those who received the detailed probe, only about half of the informal work mentioned when we probed had been included when answering the CPS employment questions. Respondents also were asked to report the number of hours devoted to the informal work reported in response to the probing question. Appendix A (Supplental material) provides information on the age, sex, education, race, and ethnicity of self-reports and proxy reports by assignment to the global versus the detailed question treatment. The question treatment groups are well balanced with respect to these characteristics. The only statistically significant differences between the characteristics of the global and detailed question treatment groups are among other household members, with those assigned the global question somewhat less likely than those assigned the detailed question to have some college or an Associate degree (30.6\% versus 36.7\%) and somewhat more likely to have a Bachelors degree or higher (40.5\% versus $36.1 \%$ ).

To answer our first research question - whether there is informal work for pay or profit done during the survey reference week that the CPS employment questions do not capture-we look at the proportion of individuals for whom additional probing identified work that was not included in the answers to the CPS questions. We use a one-tailed one sample $t$-test to determine whether this proportion is significantly greater than zero.

To address our second research question on whether the method used to probe for informal work affects the answers obtained, we compare the share of people for whom additional work is identified by the global versus the detailed question. We use a two-tailed two-sample $t$-test to determine whether the two probes-the global question and the detailed question-elicit different amounts of additional work activity. To address our third research question, we carry out these same comparisons separately for respondents reporting for themselves (self-reports) versus respondents reporting for other household members (proxy reports) and then, within the latter group, separately for respondents reporting about a spouse or unmarried partner (which we will refer to simply as a spouse) versus respondents reporting about another household member.

We are most interested in the effects that probing for informal work activity has on the estimated employment rate (the percent of people in the sample who were employed) and the multiple job holding rate (the percent of employed persons with two or more jobs). Additional work activity identified among those initially classified as not employed could raise the employment rate; additional work activity identified among those with a single CPS job could raise the multiple job holding rate. In principle, the identification of multiple jobs for someone initially classified as not employed also could raise the multiple job holding rate. For the purpose of comparing the effects of the detailed and global questions on the multiple job holding rate, however, we do not want to allow for an outcome that is possible for those receiving the detailed question but not for those receiving the global question. In contrast to the detailed question, the global question allows us to determine only that an individual had done some work that was not initially reported, not whether they had more than one unreported job.

We look first at how asking one or the other of the probing questions (either the global question or the detailed question) affects the statistics of interest (the employment rate and the multiple job holding rate). We use one-tailed paired $t$-tests to determine whether these effects pass the threshold of statistical significance. The differences in the effects of interest then are compared across the two treatments-the detailed question treatment 
versus the global question treatment-using a two-tailed two-sample $t$-test. These analyses related to our final research question are carried out first for the full sample and then separately by household member status (self-report or proxy report), with the latter also broken out according to whether the report is for a spouse or other household member.

All analyses are unweighted. The implications of the sample design and lack of weights are considered in the concluding discussion.

\section{Results}

Our first research question asks whether individuals engage in informal work during the reference week that is not captured by the standard CPS employment questions. We begin by looking at the patterns of employment for the sample as a whole. As shown in Table 2, based on their employment status as determined using the responses to the standard CPS questions, $16.6 \%$ of sample members are categorized as not employed, $63.6 \%$ as employed with one job, and $19.8 \%$ as employed with more than one job. By comparison, in CPS data for August 2016, 38.7\% of individuals 18 and older were not employed, 58.3\% were employed with one job, and $3.0 \%$ were employed with two or more jobs.

When respondents are prompted with follow-up questions about work activity outside of a regular job, additional work not reflected in the answers to the standard CPS employment questions is reported for $21.9 \%$ of the sample. Additional work is identified for members of all three employment-status groups-among those the CPS questions identified as not employed, as employed with a single job, and as employed with two or more jobs.

Because our sample was recruited through Amazon's Mechanical Turk, we know that all of our respondents have been involved in gig work at least to some extent. This means that the incidence of additional work we uncovered by probing likely is higher than in the general population. We do not have good information on the types of informal work done by those who received the global probe, but we do have that information for those who received the detailed probe. About a third of those receiving the detailed probe who did any added informal work reported work in the research category, which is where

Table 2. Additional Work Activity Identified by Probing, Full Sample.

\begin{tabular}{|c|c|c|c|c|}
\hline & $\begin{array}{l}\text { Sample } \\
\text { size }\end{array}$ & $\begin{array}{l}\text { Employment } \\
\text { status based on } \\
\text { CPS questions, } \\
\text { percent of } \\
\text { full sample }\end{array}$ & $\begin{array}{l}\text { Additional work } \\
\text { activity identified } \\
\text { by probing, } \\
\text { percent of } \\
\text { full sample }\end{array}$ & $\begin{array}{l}\text { Additional work } \\
\text { activity identified } \\
\text { by probing, } \\
\text { percent of row } \\
\text { category }\end{array}$ \\
\hline Total & 4,939 & 100.0 & 21.9 & 21.9 \\
\hline $\begin{array}{l}\text { CPS not } \\
\text { employed }\end{array}$ & 820 & 16.6 & 3.9 & 23.5 \\
\hline $\begin{array}{l}\text { CPS employed, } \\
1 \text { job }\end{array}$ & 3,142 & 63.6 & 14.8 & 23.3 \\
\hline $\begin{array}{l}\text { CPS employed, } \\
2 \text { plus jobs }\end{array}$ & 977 & 19.8 & 3.1 & 15.9 \\
\hline
\end{tabular}

${ }^{1}$ All reported values for percent in full sample with additional work activity identified by probing significantly different from zero at $p<0.001$. 
Mechanical Turk activities should be listed. Looking across the remaining categories, among those receiving the detailed probe for whom we identified added work, $17 \%$ performed services for others, $12 \%$ performed services for a business or self-employed person, $7 \%$ earned money by posting content online, $3 \%$ drove for a ride-sharing service, $3 \%$ performed as an entertainer, and $31 \%$ did other types of informal work not captured in the more specific categories. These numbers add up to slightly more than 100 percent because there were some people who reported more than one type of added work.

As a sensitivity check, using the portion of our sample that received the detailed probe, we reran the tabulations reported in Table 2 excluding all additional informal research work. Without this exclusion, $25.8 \%$ of those receiving the detailed probe reported additional work activity; excluding research work, this share was smaller but remained substantial at 19.7\%. As shown in Appendix Table B1 (Supplemental material), even with research work excluded, probing identified substantial added work activity in all three employment status groups as determined based on the answers to the CPS employment questions.

Another natural question to ask about the added work activity identified through probing is whether it involved more than a minimal amount of individuals' time. We collected information on hours for informal work identified through probing both for those receiving the global probe and for those receiving the detailed probe. Among those responding to the global probe, after asking the hours question, we then asked whether any reported informal work activity had been included when answering the CPS employment questions. Some subjects receiving the global probe could have done more than one type of informal work during the survey reference week; if the answer to the question was no, we assume that none of it had been reported. For those responding to the detailed probe, we asked separately about hours and their inclusion in answering the CPS employment questions for each type of reported informal activity. As a check on whether our conclusions would have been different had we excluded informal work activity identified through probing that involved only a minimal amount of time, we recomputed the numbers reported in Table 2 but counting added informal work only for those with at least four hours of such work identified through probing. As can be seen in Appendix Table C1 (Supplemental material), the share of respondents with added work is about 40 percent lower - $13.0 \%$ rather than $21.9 \%$ - but the general trends in the estimates are otherwise unaffected.

Among the full set of people reporting additional work during the survey reference week after probing, including those with very low hours, some $17.6 \%$ said that they spent an estimated 15 or more hours on that additional activity $(15.2 \%$ for those receiving the global probe and $19.3 \%$ for those receiving the detailed probe). Added work activity during the reference week identified through probing occupied an average of 8.2 hours during the survey reference week ( 7.0 hours for those receiving the global probe and 9.1 hours for those receiving the detailed probe), roughly equivalent to a full normal work day. Those with no CPS employment for whom unreported work activity was identified by probing are somewhat more likely than those with one or more CPS jobs to have spent 15 or more hours on that activity during the reference week $(24.7 \%$ versus $16.0 \%$ overall, $17.1 \%$ versus $14.9 \%$ for those the receiving the global probe, and $29.2 \%$ versus $16.9 \%$ for those receiving the detailed probe). Among those for whom added work activity was 
identified, the group with no CPS employment also spent more hours than those with one or more CPS jobs (9.9 versus 7.9 hours overall, attributable entirely to the difference of 11.8 versus 8.5 hours for those receiving the detailed probe).

Our second research question asks whether the form of the follow-up question about informal work affects the number of people for whom additional work activity is identified. The first two rows of Table 3 report estimates of the distribution of the sample by CPS employment status and the distribution of additional employment identified by probing across the three employment status groups. Here, these estimates are shown separately for the cases receiving the global prompt and those receiving the detailed prompt. As anticipated given that the assignment to the global versus the detailed probe was random, the shares of the sample cases in each of the three CPS employment status groups do not differ significantly between the two treatments. The share of cases for which added employment was identified through probing, however, is significantly greater under the detailed question treatment than under the global question treatment $(25.8 \%$ versus $18.0 \%$, a statistically significant difference of 7.8 percentage points). This overall difference is spread across individuals with no CPS employment, one CPS job, and more than one CPS job; in each of the three groups, the detailed question identifies significantly more added employment than does the global question.

The third research question we posed was whether the effects of prompts to uncover work activity outside of a regular job differ depending on whether they apply to the individual herself (self-report) or to another household member (proxy report) and, in the latter case, whether the effects differ according to the relationship between the respondent and the other household member. The next two panels of Table 3 report estimates separately for the self-report and proxy report cases in our sample. The prevalence of work activity reported in response to the CPS questions is much higher for the people for whom we obtained self-reports than for the people for whom we obtained proxy reports. Those in the self-report group are much less likely to have no CPS employment, equally likely to have a single CPS job, and much more likely to have two or more CPS jobs. Consistent with the random assignment of respondents to treatments, within each of these two groups (self-reports and proxy reports), there are no significant differences in the prevalence of work activity elicited by the standard CPS questions between those receiving the global prompt and those receiving the detailed prompt.

The self-report cases in our sample differ from those for whom we have proxy reports not only in their level of work activity as captured by the CPS questions but potentially also with respect to the prevalence and nature of any work activity not captured by those questions. Differences in the amount of additional work activity identified by prompting for the self-report cases versus the proxy report cases could be due to differences in how people report about themselves as compared to how they report about others. They also could be due, however, to real differences in the labor force activity of the self-reports versus the proxy reports. Given that respondents were assigned randomly to be asked the detailed question versus the global question, however, we can attribute differences across question treatments within either the self-report or the proxy report group to the type of probe each treatment group received.

Asking the detailed question rather than the global question raises the share of proxy report cases for which additional work activity is identified by 10.2 percentage points, 


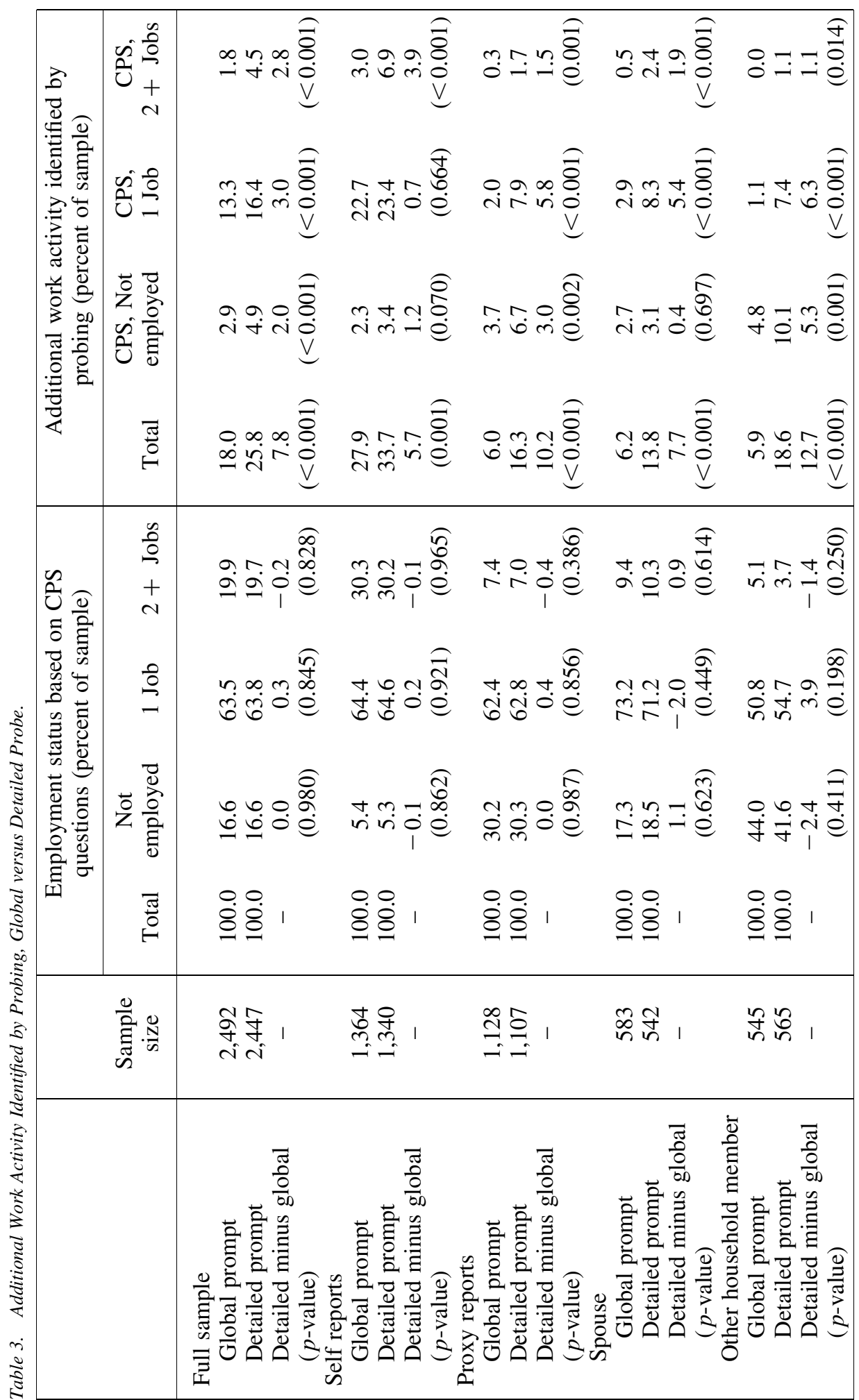


from $6.0 \%$ of cases with added work activity using the global prompt to $16.3 \%$ of cases using the detailed prompt. In contrast, the difference for the self-report cases is just 5.7 percentage points, with $27.9 \%$ reporting added work activity under the global prompt versus $33.7 \%$ under the detailed prompt. Putting these results somewhat differently, the number of proxy report cases with additional work identified by probing increases by $172 \%$ when the detailed question is asked instead of the global question, compared to an increase of just $21 \%$ for the self-report cases. Asking the detailed rather than the global question also has a larger effect on the number of hours devoted to additional work for proxy report cases for whom additional work is identified (11.1 hours versus 6.5 hours, a 4.6 hour difference) than for self-report cases with additional work (8.3 hours versus 7.1 hours, a 1.2 hour difference). Among the proxy reports, there are significant differences in the amount of additional work activity identified by the detailed prompt versus the global prompt for all three employment status groups - those without CPS employment, those with one CPS job, and those with more than one CPS job. Among the self-report cases, however, the only statistically significant difference arises for the subgroup who already had reported more than one job in response to the standard CPS questions.

The bottom two panels of Table 3 further break out how asking the global versus the detailed question affects the additional work activity reported when a proxy is answering for a spouse or unmarried partner (referred to for convenience as a spouse) versus some other household member. The rationale for making this comparison is that we expect a respondent generally to be closer to her spouse than to other household members and to communicate more with her spouse about daily activities. If this is correct, we might expect the amount of additional work activity identified by the global compared to the detailed questions be more similar when the proxy subject is a spouse than when the proxy subject is some other household member.

Among reports for spouses, the global and the detailed questions perform very similarly with respect to identifying previously unreported work activity for those with no CPS job, though a second or third job is more likely to be reported when the detailed question is asked. Among reports for other household members, the detailed question elicits significantly more reports of additional employment than the global question for all three CPS employment status groups (no CPS employment, one CPS job, or two or more CPS jobs). This is consistent with stronger cues being more important for activating respondents' memories or encouraging respondents to make use of situational knowledge when they are reporting for household members other than their spouse. Both for spouses and for other household members, among those with additional work identified, the detailed probe has a larger effect than the global probe on the number of hours reported (11.0 versus 6.1 hours for spouses and 11.2 versus 6.9 hours for other household members).

Because we have good information about the type of informal work performed only for respondents asked the detailed question, we cannot repeat this analysis with research work excluded. We have replicated the Table 3 tabulations excluding added work that involved less than four hours during the reference week. These results are shown in Appendix Table C2 (Supplemental material). As in our baseline results, the detailed probe elicits more unreported work activity than the global probe. This is especially true for proxy reports and, among the proxy reports, for other household members rather than a spouse. 
Table 4 examines how taking into account the additional work activity identified by probing affects the estimated employment rate, defined as the share of the sample employed during the survey reference week, and the estimated multiple job holding rate, defined as the share of CPS employed persons holding more than one job during the reference week. The table reports estimated rates based on the responses to the CPS questions; augmented rates that add the additional work activity identified by probing to the numerator used to calculate the rate in question; and differences between each pair of estimated rates. In the full sample, as shown by the numbers in the first two rows of the table, probing to identify additional work activity consistently raises both the employment rate and the estimated multiple job holding rate. The increase in the employment rate is larger for those who received the detailed probe than for those who received the global probe. The difference in the effects of the detailed versus the global probe on the estimated employment rate in the full sample is a statistically significant 2.0 percentage points. Both the global and the detailed probe produce substantially larger effects on the multiple job holding rate. Again, in the full sample, the effect is larger with the detailed probe, which raised the multiple job holding rate by a statistically significant 3.6 percentage points more than the global probe.

Disaggregating by whether the respondent is reporting for herself or for another household member makes clear that the differences in the effects on the employment rate we observe in the full sample for the detailed question versus the global question arise primarily among the proxy report cases. For proxy reports, the effect on the employment rate of incorporating additional work activity identified by probing is a statistically significant 3.0 percentage points larger based on asking the detailed question as opposed to the global question. For the self-report cases, the corresponding difference in employment rate effects is smaller (1.2 percentage points) and not statistically significant.

The same general pattern holds for the multiple job holding rate. For proxy reports, incorporating additional work identified by probing raises the multiple job holding rate by a statistically significant 8.4 percentage points more when the detailed question is asked than when the global question is asked. For self-reports, in contrast, although both the detailed and the global question questions identify a sizable number of second jobs not reported in response to the CPS questions, the difference between the two effects is small and statistically indistinguishable from zero.

As with the results reported in Table 3, there is heterogeneity within the proxy report cases. Results are shown separately for spouses and other household members in the bottom two panels of Table 4. Recall that, among those reporting about themselves, the global and the detailed questions have statistically indistinguishable effects on both the employment rate and the multiple job holding rate. In the reports for spouses, the effect on the employment rate of asking the detailed question is statistically indistinguishable from the effect of asking the global question, but asking the detailed question has a notably larger effect on the multiple job holding rate. Adding work activity identified by probing raises the multiple job holding rate for a spouse by a statistically significant 6.7 percentage points more when the detailed question is asked than when the global question is asked. Finally, among reports for other household members, asking the detailed question rather than the global question has a larger effect on both the employment rate and the multiple job holding rate. 


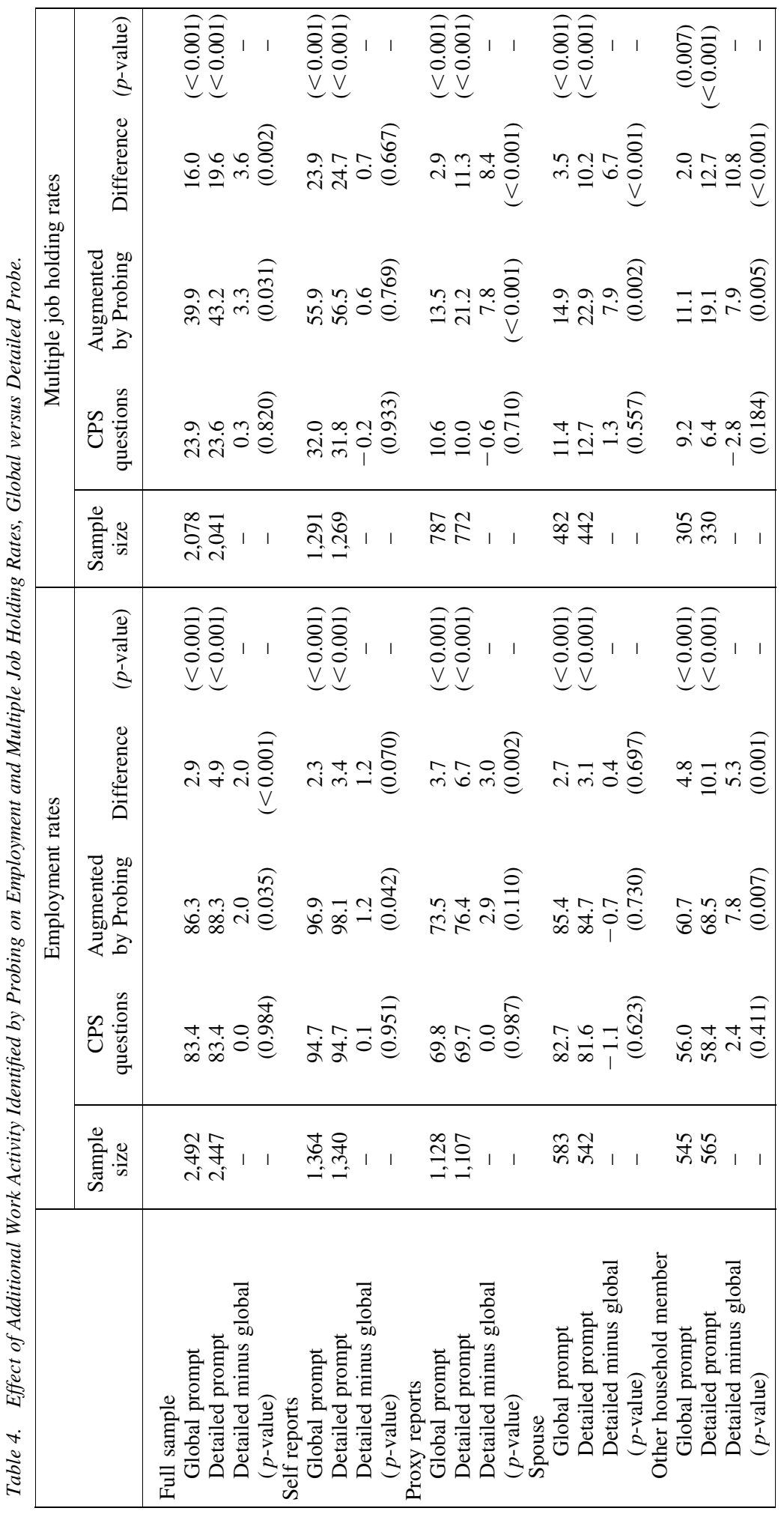


To assess the sensitivity of these findings, we have replicated the Table 4 tabulations for respondents who received the detailed prompt but with added research work excluded (results reported in Appendix Table B2, Supplemental material). We also have replicated the full Table 4 analysis but with added work involving less than four hours during the reference week excluded (results reported in Appendix Table C3, Supplemental material). Even with these exclusions, incorporating the added work identified by probing produces a statistically significant increase in the estimated employment rate and has an even larger effect on the estimated multiple job holding rate. In the tabulations that exclude added work involving less than four hours, we can examine the effects of asking the detailed versus the global question about informal work. All of the qualitative findings from our Table 4 analysis are robust to the exclusion of very-low-hours added work.

\section{Discussion and Conclusion}

The results we have reported suggest that there may be a substantial number of people involved in informal work that is not captured by the standard CPS questions. In our sample, additional probing using either a global question or a decomposed question identified a sizeable number of reports of additional work activity. This was true whether a respondent was reporting for themselves or for another household member, and also whether the other household member was a spouse or someone else. Accounting for this additional work activity raised both the employment rate and the multiple job holding rate, defined in each case in the same way as in the monthly labor force statistics published by the BLS.

Further, our results suggest that different ways of probing for additional work activity may produce different results depending on the person about whom a respondent is reporting. For those in our sample reporting about themselves, the effects of a global probe are not very different from the effects of a more detailed probe that decomposes various possible types of work activity a person might have carried out and provides examples. Among these self-reports, the detailed probe elicits a significantly greater number of reports of additional work activity only for those who already had mentioned two or more jobs in response to the standard CPS questions. In contrast, for proxy reports, the detailed probe more consistently elicits a greater number of such reports. This is especially true when a respondent is reporting for a household member other than her spouse.

For a self-report, asking the detailed question rather than the global question has essentially the same effect as asking the global question on both the employment rate and the multiple job holding rate. For reports about a spouse, asking the detailed question produces a larger effect on the multiple job holding rate but not the employment rate. Finally, for reports about other household members, asking the detailed question has a larger effect on both the employment rate and the multiple job holding rate.

The added work activity identified through probing in our survey most likely is attributable either to respondents not having understood that this activity should have been reported in answering the CPS employment questions or to the cue offered by the probe activating their memories of the activity. The fact that, for self-reports, the detailed probe generally does not produce larger effects than the global probe may suggest that memories about own recent work activity tend to be relatively accessible. In contrast, for proxy 
reports - and especially proxy reports pertaining to household members other than the spouse - the detailed probe more consistently produces more reports of added work activity, suggesting that strong cues are likely to be useful when seeking information from household survey respondents about work done by others in their households.

An important limitation of our study is that the sample for which we collected data is not representative of the population as a whole. All of our respondents are individuals who are active on Mechanical Turk and thus likely (though not certain) to have been involved at least in that form of informal work activity during the survey reference week. We would not expect the same necessarily to be true of other members of respondents' households, but even that group is younger and more educated than the population as a whole and may be atypical in other respects. For these reasons, even if we were to reweight the data we have collected to match the observable demographic characteristics of the broader population, the estimates derived from our survey responses could not be generalized to that universe. Another caution about drawing conclusions from our study about biases in the responses to the CPS employment questions is that our survey was conducted online, whereas the CPS responses are collected via telephone or face-to-face interviews. The survey findings nonetheless provide important evidence about the sensitivity of survey estimates to asking more probing questions and structuring the probes in different ways.

To the extent that irregular or informal work has become more common, underreporting of work activity in response to the standard CPS questions could have become more prevalent over time. The fact that the share of people reporting self-employment income on their tax returns has been rising while the share reporting self-employment income in household survey data has been flat or declining is consistent with this possibility (Katz and Krueger 2019b; Abraham et al. 2018). On the other hand, surveys designed specifically to capture informal work activity do not show continued overall growth in the rate of participation in such activity in recent years, though participation in online platform work appears to have become more prevalent and cyclical effects could have masked a continuation of an underlying positive trend (Bracha and Burke 2018). It is important in any case to understand clearly what the CPS employment questions are and are not capturing, and to think about whether and how they could be improved or supplemented.

As the agency responsible for producing official U.S. labor force statistics, the BLS has a strong interest in producing the best possible information about individuals' work arrangements and how they are evolving. The Contingent Work Supplement (CWS) to the CPS, administered on five occasions between 1995 and 2005 and again in 2017, provides valuable information on this topic (see, e.g., Polivka 1996, Cohany 1996, and Bureau of Labor Statistics 2018). Because the CWS takes as its starting point the employment reported in response to the standard CPS questions, asking additional questions only about the main job reported for each person, it provides no information about any work not reported in answer to the standard CPS questions or work that is secondary to a main job. There is a need, we would argue, for efforts to design questions that can be used to obtain information about informal work more broadly. That said, if the types of informal work that people are doing change over time, the questions that are most appropriate to ask may change as well, something that could make it more difficult to produce estimates of informal work activity that are consistent over time. 
In future research, it would be of value to examine whether our findings can be replicated in samples that have different characteristics and, ideally, are more representative of the general population. There also would be value in replicating our analysis using the survey modes that are employed in the CPS (telephone and face-to-face interviews) rather than collecting responses to an online instrument. In this study, we have compared the effects of asking a global question to the effects of asking a particular decomposed question for learning about informal work not reported in response to the standard CPS questions. The categories and examples included in our decomposed question focused on activities in which compensation is received mainly for a person's labor, as opposed to being provided in connection with selling a product (e.g., selling crafts on e-Bay) or providing temporary use of a capital asset (e.g., renting out a room in a house through Airbnb). It is not yet clear, however, which categories and examples of activities should be mentioned to obtain the most complete accounting of work done for pay or profit. Further research on how best to ask about such activity would be desirable. Additional testing also might incorporate follow-up questions about when any added activities were performed (to determine whether and to what extent activities that occurred prior to the survey reference period may have been reported), how much was earned from any missed activities (as a means of gauging their importance), and why the activities were not reported initially.

\section{References}

Abraham, K.G., J.C. Haltiwanger, K. Sandusky, and J.R. Spletzer. 2018. "Measuring the Gig Economy: Current Knowledge and Open Issues." National Bureau of Economic Research Working Paper No. 24950. August. Doi: http://dx.doi.org/10.3386/ w24950.

Abraham, K.G. and S.N. Houseman. 2018. "Making Ends Meet: The Role of Informal Work in Supplementing Americans' Income.” Upjohn Institute, unpublished working paper. December. Available at: https://www.aeaweb.org/conference/2019/preliminary/ paper/QreAaS2h (accessed July 2019).

Allard, M.D. and A.E. Polivka. 2018. "Measuring Labor Market Activity Today: Are the Words Work and Job Too Limiting for Surveys?" Monthly Labor Review. November. Available at: https://www.bls.gov/opub/mlr/2018/article/pdf/measuring-labor-marketactivity-today.htm (accessed April 2019).

Belli, R.F., N. Schwarz, E. Singer, and J. Talarico. 2000. "Decomposition Can Harm the Accuracy of Behavioural Frequency Reports." Applied Cognitive Psychology 14: 295-308. Doi: http://dx.doi.org/10.1002/1099-0720(200007/08)14:4<295::AID-ACP 646>3.0.CO;2-1.

Blair, E. and S. Burton. 1987. "Cognitive Processes Used by Survey Respondents to Answer Behavioral Frequency Questions." Journal of Consumer Research 14(2): 280-288. Doi: https://doi.org/10.1086/209112.

Board of Governors of the Federal Reserve System. 2017. Report on the Economic WellBeing of U.S. Households in 2016. Washington, D.C: Board of Governors of the Federal Reserve System. Available at: https://www.federalreserve.gov/publications/files/2016report-economic-well-being-us-households-201705.pdf (accessed May 2019). 
Bower, G.H. and S.G. Gilligan. 1979. "Remembering Information Related to One's Self." Journal of Research in Personality 13: 420-432. Doi: https://doi.org/10.1016/00926566(79)90005-9.

Bracha, A. and M.A. Burke. 2018. "The Ups and Downs of the Gig Economy, 2015-2017." Federal Reserve Bank of Boston Working Paper 18-12. October. Available at: https://www.bostonfed.org/publications/research-department-working-paper/2018/theups-and-downs-of-the-gig-economy-2015-2017.aspx (accessed May 2019).

Bracha, A. and M. A. Burke. 2019. "How Big is the Gig?" Federal Reserve Bank of Boston, unpublished working paper. January.

Brown, N.R., L.J. Rips, and S.K. Shevell. 1985. "The Subjective Dates of Natural Events in Very-Long-Term Memory." Cognitive Psychology 17(2): 139-177. Doi: https://doi.org/10.1016/0010-0285(85)90006-4.

Bureau of Labor Statistics. Undated. "Labor Force Statistics from the Current Population Survey: Frequently Asked Questions.” Available at: https://www.bls.gov/cps/faq.htm (accessed June 2018).

Bureau of Labor Statistics. 2018. "Contingent and Alternative Employment Arrangements, May 2017." Available at: https://www.bls.gov/news.release/pdf/conemp.pdf (accessed June 2018).

Cohany, S.R. 1996. "Workers in Alternative Employment Arrangements." Monthly Labor Review. October: 31-45. Available at: https://www.bls.gov/mlr/1996/10/art4full.pdf (accessed May 2019).

Dashen, M. 2000. "The Effects of Retention Intervals on Self- and Proxy Reports of Purchases." Memory 8(3): 129-143. Doi: https://doi.org/10.1080/096582100387560.

Fowler, F.J., Jr. 1992. "How Unclear Terms Affect Survey Data." Public Opinion Quarterly 56(2): 218-231. Doi: https://doi.org/10.1086/269312.

Katz, L.F. and A.B. Krueger. 2019a. "Understanding Trends in Alternative Work Arrangements in the United States.” NBER Working Paper No. 25425. Cambridge, MA: National Bureau of Economic Research. Doi: https://doi.org/10.3386/w25425.

Katz, L.F. and A.B. Krueger. 2019b. "The Rise and Nature of Alternative Work Arrangements in the United States, 1995-2015.” ILR Review 72(2): 382-416. Doi: https://doi.org/10.1177\%2F0019793918820008.

Kojetin, B.A. and L.A. Miller. 1993. "The Intrahousehold Communications Study: Estimating the Accuracy of Proxy Responses at the Dyadic Level." Paper presented at the 48th Annual Conference of the American Association for Public Opinion Research, St. Charles, Illinois. May. Available at: http://www.asasrms.org/Proceedings/papers/ 1993_188.pdf (accessed May 2019).

Kuiper, N.A. and T.B. Rogers. 1979. "Encoding of Personal Information: Self-Other Differences." Journal of Personality and Social Psychology 37(4): 499-514. Doi: http://dx.doi.org/10.1037/0022-3514.37.4.499.

Martin, E. 2006. "Survey Questionnaire Construction." U.S. Census Bureau Research Report Series, Survey Methodology \#2006-13. Available at: https://www.census. gov/srd/papers/pdf/rsm2006-13.pdf. (accessed May 2019).

Martin, E. and A.E. Polivka. 1995. "Diagnostics for Redesigning Survey Questionnaires: Measuring Work in the Current Population Survey." Public Opinion Quarterly 59(4): 547-567. Doi: https://doi.org/10.1086/269493. 
Menon, G. 1997. "Are the Parts Better than the Whole? The Effects of Decompositional Questions on Judgments of Frequent Behaviors." Journal of Marketing Research 34(3): 335-346. Doi: https://doi.org/10.1177\%2F002224379703400303.

Phillips, J.M., B.A. Bickart, and G. Menon. 2006. "Reporting About Others' Behavior: The Role of Judgment Strategy, Knowledge, and Regularity." September. Available at: https://ssrn.com/abstract=946247 (accessed April 2019).

Polivka, A.E. 1996. “A Profile of Contingent Workers.” Monthly Labor Review. October: 10-21. Available at: https://www.bls.gov/opub/mlr/1996/article/profile-of-contingentworkers.htm (accessed May 2019).

Robles, B. and M. McGee. 2016. Exploring Online and Offline Informal Work: Findings from the Enterprising and Informal Work Activities (EIWA) Survey. Washington: Board of Governors of the Federal Reserve System. Doi: https://doi.org/10.17016/ FEDS.2016.089.

Schober, M.F. and F.G. Conrad. 1997. "Does Conversational Interviewing Reduce Survey Measurement Error?" Public Opinion Quarterly 61(4): 576-602. Doi: https:// doi.org/10.1086/297818.

Schober, M.F., A.L. Suessbrick, and F.G. Conrad. 2018. "When Do Misunderstandings Matter? Evidence from Survey Interviews about Smoking." Topics in Cognitive Science 10(2): 452-484. Doi: https://doi.org/10.1111/tops.12330.

Schwarz, N. 1999. "Self-Reports: How the Questions Shape the Answers." American Psychologist 54(2): 93-105. Doi: http://dx.doi.org/10.1037/0003-066X.54.2.93.

Schwarz, N. and T. Wellens. 1997. "Cognitive Dynamics of Proxy Responding: The Diverging Perspectives of Actors and Observers." Journal of Official Statistics 13(2): 159-179. Doi: https://doi.org/10.1.1.39.5355.

Sudman, S. and N.M. Bradburn. 1973. "Effects of Time and Memory Factors on Response in Surveys." Journal of the American Statistical Association 68: 805-815. Doi: https://doi.org/10.2307/2284504.

Sudman, S., N.M. Bradburn, and N. Schwarz. 1996. Thinking About Answers: The Application of Cognitive Processes to Survey Methodology. San Francisco: Jossey-Bass.

Tourangeau, R. 2000. "Remembering What Happened: Memory Errors and Survey Report." In The Science of Self-Report: Implications for Research and Practice, edited by A.A. Stone, C.A. Bachrach, J.B. Jobe, H.S. Kurtzman, and V.S. Cain, 29-47. Mahwah, NJ: Lawrence Erlbaum Associates Inc.

Tourangeau, R., F.G. Conrad, M.P. Couper, and C. Ye. 2014. "The Effects of Providing Examples in Survey Questions.” Public Opinion Quarterly 78(1): 100-125. Doi: https://doi.org/10.1093/poq/nft083.

Tourangeau, R., L.J. Rips, and K. Rasinski. 2000. The Psychology of Survey Response. New York: Cambridge University Press.

U.S. Census Bureau. 2006. Design and Methodology: Current Population Survey, Technical Paper No. 66. Washington DC. Available at: https://www.census.gov/prod/ 2006pubs/tp-66.pdf (accessed July 2019).

Received August 2018

Revised January 2019

Accepted May 2019 